\title{
ADVANCED REACTOR INSTRUMENTATION AND CONTROL RELIABILITY AND RISK ASSESSMENT *
}

\author{
R. Fullwood, W. Gunther, J. Valente, and M.A. Azarm BNL--47163 \\ Brookhaven National Laboratory. \\ Department of Nuclear Engineering \\ DE92 010147
}

\section{Summary}

Advanced nuclear power reactors will use different approaches to achieving a higher level of safety than the first generation. One approach uses the technological developments in computation and electronics in the form of digital instrumentation and control ( $\mathrm{Y} \& \mathrm{C}$ ) to enhance the reliability, and accuracy of information for plant control, responding to the information, and controlling the plant and its systems under normal and upset environments in various states of degradation. Evaluating the reliability and safety of advanced $I \& C$ systems requires determining the reliability of the I\&C used in the advanced reactors which involves distributed processing, data pile-up, interactive systems, the man-machine interface, various forms of automatic control, and systems interactions. From these analyses will come an understanding of the potential of the new $I \& C$, and protection from its vulnerabilities to enhance the safe operation of the new plants.

Technological, safety, reliability, and regulatory issues associated with advanced I\&C for the new reactors are discussed herein. The issues are presented followed by suggested approaches to their resolution.

\section{Background}

The basic design of U.S. nuclear power plants was developed in the late 1950's and early 1960's. Computers at this time were programmed with patch panels, used vacuum tubes and had less computing power than some modern hand calculators. Instrumentarion and eontrol (I\&C) of plants at the time reflected the state of technology. Upgrades of old systems have been performed, such as microprocessor control of the feedwater control val ve in a 20-year old BWR-1, but the application of these electronics advances to nuclear power is just beginning to appear.

While advanced reactors use different equipment from the older plants, the basic principles remain the same, as illustrated in Figure 1. Plant status information is collected, processed and oransmitted to operators or automatic control systems from which come the control signals. This is shown in the figure for advanced $5 \& C$ : The sensors, continuously monitoring the parameiers, produce analog electrical signals which undergo various types of signal conditioning before going to distributed processors for digital conversion and mulriplexing onto transmission systems linking with central

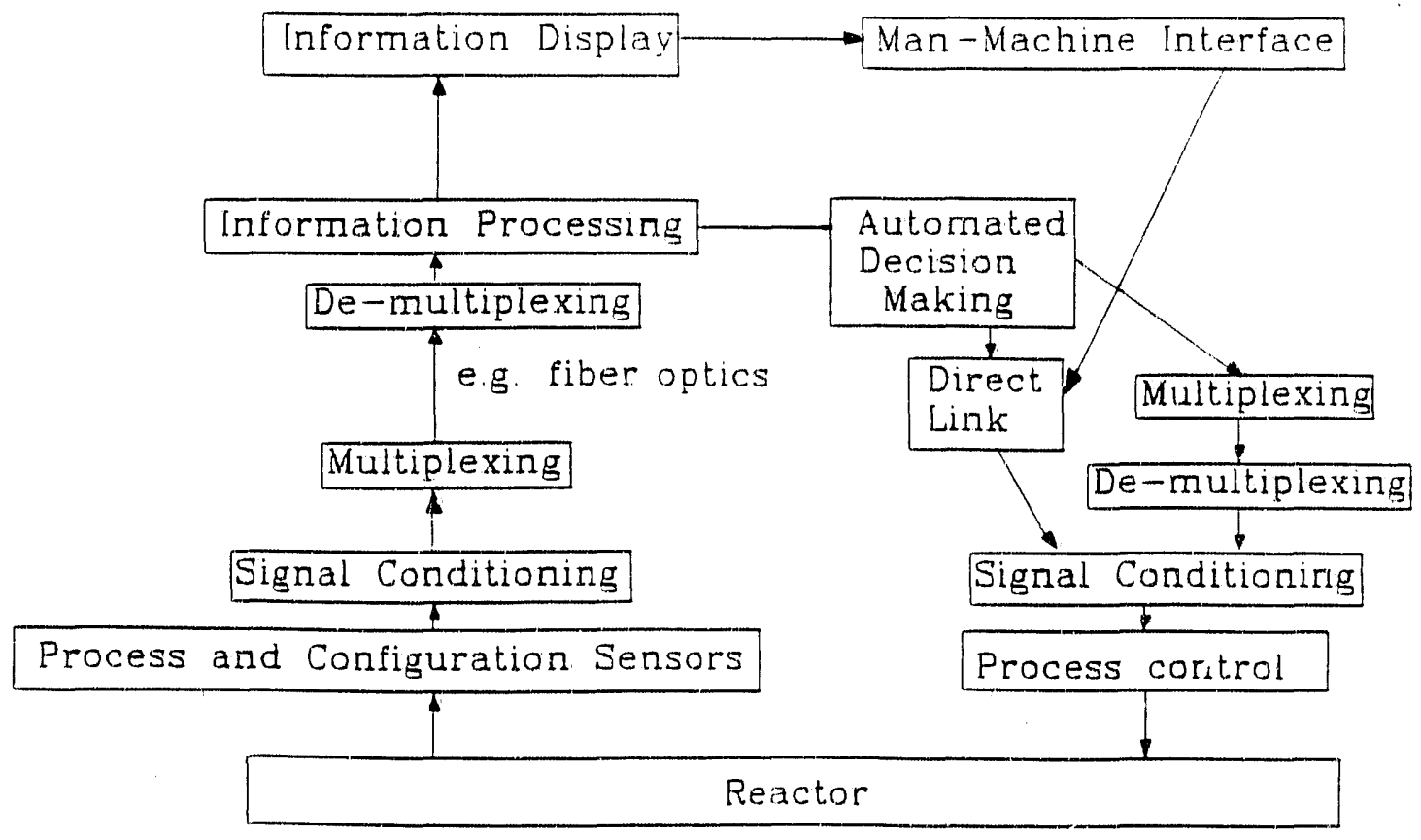

Generic Reactor Control

*This work was performed under the auspices of the U.S. Department of Energy. 
processing locations prior to operator display or use as input to automatic control systems. The distributed processors are special-purpose microcomputer systems with the necessary software for their control and decision-making. Transmission media are fiber-optics or transmission lines. As an example, the Westinghouse AP600 design uses a "Monitor Bus", as a high speed, redundant communications network to link systems important for operator control of the plant. Safety-related systems use isolation devices for ground loop isolation and for protection against failures elsewhere.

The exact way this process is executed varies with the vendor's grouping of distributed processing, the types of links, parallel processing and central processing. As there is a generic form of the $I \& C$, there are generic and specific problems that are unique to advanced I\&C. Table 1 presents some concerns associated with digital control of advanced nuclear power plants followed by suggested approaches.

Table 1. Some Regulatory Concerns Associated with Advanced I\&C

1) Risk and Reliability Evaluation Methods

2) Analyzing Information Processing Overload

3) Data Sources for Reliability Analysis,

4) Software Reliability Analysis,

5) System Interactions/Common Cause of Failure,

6) Environmental Considerations,

7) Signal Validation and Disturbance Analysis,

8) Test, Mainterance, Education and Training,

9) Man-Machine Interface,

10) Adequacy of Codes, Guides, and Standards for Evaluating Advanced I\&\&.

\section{RISK AND RELIABILITY EVALUATION METHODS}

\section{Discussion}

Advanced I\&C consists of hardware and software providing either direct feedback in the form of automated control, or feedback as an operator aid to facilitate the conduct of plant operation within acceptable limits imposed by the plant Technical Specifications. Conventional techniques for reliability and risk analyses may not be adequate for advanced I\&C systems because of feedback loops and timing considerations. Fault trees find their greatest validity when used for the analysis of static situations. In dynamic situations, such as where success or failure causes reconfiguration such as occurs in adaptive, fed-back systems, it may be necessary 10 modify fault tree analysis (FTA) or adopt other analytical approaches. Determining the reliability of these systems may necessitate either extensions of FTA or the use of alternative methods such as Digraph and Markov.

\section{Approach.}

A design for advanced reactor licensing will be carefully examined and evaluated to determine the adequacy of current methods. Adaptive, fed-back systems will be identified, evaluated for criticality to plant safety and investigated by several approaches. One method, an adaption of current fault tree practices is Phased Fault Tree Analysis (PFTA) in which time is divided into discrete segments and the system evaluated at each time step. Minimization of the number of time steps may be accomplished selecting the times for occurrence at the times of major changes. This process is closely related to finite element and mesh analysis used in many engineer. ing computer codes. Digraph, which has inherent capabilities for adaptive analysis, will also be investigated. Markov methods because of their "state change approach" may also be useful.

\section{ANALYZING INFORMATION PROCESSING OVERLOAD}

\section{Discussion}

The data rate from each sensor is determined by the time response required of each sensor. The data rate is riot particularly high from a given sensor but the rate from hundreds of sensors as it is presented to distributed processors is very high. Under normal operating conditions, the design snould adequately accommodate this problem; under accident conditions including equipment degradistion (bardware and/or software failure), the performance may not te as expected. Advanced power plants use multiple: distributed processors. In one design, accident conditions were caused by delay in information processing in an overloaded distributed processor.

\section{Approach}

Phased Fault Tree Analysis (PFTA), one form of which was suggested for the analys is of feed-back, is suggested for application on a larger scale involving interacting systems. This technique consists of fault tree analy sis performed on the control system at discrete. writ. ical time steps of operation. In application, it would involve preparing fault trees of the digital control system at the necessary levels of detail at each of the critical time. steps. Through a study of the time cycles, critica! time periods would be identified under varicas degrees of upset. It is believed that, given generic trees, major changes will not be recuired to condition a tree system for each of the time steps. While the overall trees may not require reconotruction, be changes characteristic of . time step will be significant and identify the syitem aspects that are involved. Also of concern is the design adequacy for sufficient storage and display of parameters 
under severe accident conditions. The PFTA will initially be used qualitatively for minimum cusset identification. Quantification may be performed if it is necessary to determine the probabilities of failure.

\section{DATA SOURCES FOR RELIABILITY ANALYSIS}

\section{Discussion}

Failure data are not readily available for the new electronic components that are used in advanced $I \& C$. However, the U.S. Department of Defense has done extensive analysis of complex electronic systems and prepared data bases (e.g. ML-HDBK-217E and GLDEP). Some of these data are for operating systems of comparable complexity in various environments. Some of the data are for use as input for modeling electronic systems from basic elements (MIL-HDBK-217E).

\section{Approach}

Advanced I\&C proposed for the new reactors will be examined for data base requirements. The data bases used by applicants for modeling digital control systems will be examined for adequacy and compared with data from other sources such as military and industry data. Cases of inadequate critical data will be brought to the attention of the NRC with recommendations for testing or other forms of data acquisition. Design requirements with appropriate documentation should be standardized.

\section{SOFTWARE RELIABILITY ANALYSES}

\section{Discussion}

Computers consist of hardware that is controlled by software. Software failure may cause the hardware to fail, thus software must be assured to operate properly under all circumstances especially accident conditions.

There are important differences between physical devices and software that invalidate some of the common risk assessment procedures when applied to hardware controlled by software. Software does not fail from physical wear like a mechanical component, it fails due to design and coding error. Generally, such failures are not included in the PRAs. Furthermore software repairs involve changing the program thereby rendering questionable the applicability of a conventional reliability data base for software. There are three types of software tests: static, dynamic and application.

Static testing consists of such tools as data-flow analyzers to check data path consistence, path analyzers to follow the program's path and assure against "deat code", coverage analyzers to assure that all paths are tested, interface analyzers to examine variable passing, and cross references of symbolic names. Dynamic testing tools include assertion checkers which insert probes into the code and flag wolations of the programmer's "assertion", simulators that mimic hardware or missing codes, path-flow tracers to trace program logic under dynamic conditions, symbolic execution tools to execute arithmetic with symbolic variables, and mutation analyzers that place intentional errors in a program for a set of test cases. Application testing consists of operating the software with its hardware to perform key tests under simulated accident conditions. Clearly the last type of testing is the most definitive for the tests that are performed. The problem with this type of testing is assuring that the set of tests is exhaustive.

\section{Approach}

The vendor's test program will be examined to determine the structure of the cade and the tests that have been performed. BNL will use various analytical models to consider the conirol system response, as controlled by the software, to each accident initiator from a full set of accident initiators. If the software passes these tests, the response to multiple combinations of initiators will be considered until the probability of multiple occurrences is less than sume cut-off value agreed upon. Detailed analyses and review may be performed using Software Fault Tree Analyses (SFTA) to identify the sottware vulnerability through qualitative rather quantitative ranking. Software test strategies, as described, will be used to detect and resolve previously undiscovered errors.

An investigation will be conducted to determine minimum standards and documentation that should be provided for the licensing process.

\section{SYSTEM INTERACTIONS/COMMON CAUSE OF FAILURE}

\section{Discussion}

The use of large scale integration, distribured processing, and a few wide-bandwidth data links provicie savings and simplicity but results in critical paths and common causes of failure which could be criticil to understanding and controlling the reactor.

\section{Approach}

BNL applies tools for common cause such as sneak circuit analysis, response matrix and interactive fault tree analysis to the digital control systems of the advanced reactors to identify any "Achilles' heels" and if such are identified, determine an approximate probabii. ity as a measure of criticality. 


\section{ENVIRONMENTAL CONSIDERATIONS}

\section{Discussion}

The extensive use of solid-state equipment raises questions of its operability under conditions of EMI (electro-magnetic interference), radiation, temperature, humidity and vibration. For example, continued operation at high temperature may cause accelerated aging not anticipated in the original design.

\section{Approach}

An exhaustive list of adverse conditions prepared and digital control systems will be analyzed under each of them. Conditions that could be detrimental to the reactor operation will be identified and importance ranked according to severity and probability according to the following subjects:

EMI: Scenarios such as in-plant electrical problems leading to arcing, will be examined regarding induced voltages that may be expected in key I\&C equipment and whether such voltages approach logic levels. If such could occur, a determination will be made regarding the estimated effect. The extensive technology developed for analysis and hardening against EMP (electro-magnetic pulse) performed for the military. will be used as appropriate.

Radiation: Solid-state equipment, unless hardened, is more susceptible to radiation and radiation degradation than conventional equipment. The layout of advanced reactors will be examined for the effects of all types of radiation in equipment such as the effects of F-center darkening of fiber-optic links or the possibility of Cerenkov radiation in these links.

Temperature: Solid-state equipment is more temperature sensitive than some conventional equipment and may be adversely affected by accident conditions. Accident temperature profiles will be developed and the effects on components, including aging, would be determined by Arrtienus or other acceptable modeling methods.

Humidity: At logic level voltages and small currents, sneak circuits such as may be caused by humidity could significantly affect safety systems. Humidity profiles under accident conditions will be examined to identify circuit boards that may be affected.

Vibration: The connectors used with digital equipment and the boarc's themselves have susceptibility to either continuous or upset conditions vibration. Such vibration levels will be identified and the equipment examined, either using results from vibration testing, or by inspection to determine vibrational susceptibility.

\section{SIGNAL VALIDATION AND DISTURBANCE ANALYSIS}

\section{Discussion}

Signal validation is concerned with assuring the correctness of a measurement. It is common practice to use multiple sensors and compare their signals for being within range and in comparison with other signals. Various physical models may be used in the comparison to determine the signal reasonableness. If a signal is found to be erroneous, software may substitute the expected value or disregard the information and use the other indicators. These signal validation techniques also identify failed instrument channels. The validity of the algorithm used for signal validation for critical safety systems needs investigation.

A related subject is disturbance analyses used in advanced I $\& C$ systems. Whereas signal validation only involves intercomparisons with sensors of the same parameter, disturbance analysis works with a.plant mode! to determine if all of the instrumentation is self-consistent and by doing this provides guidance for the analysis of disturbances to the operators.

\section{Approach}

Signal validation methods will analyze the algorithm being used, its validity and weaknesses. Estimates may be calculated regarding the possibility of an erroneous indication in spite of the validation.

Disturbance analysis methods being employed by an applicant will be reviewed regarding the model being used, its simplifications, and its possibility for providi ig the operator with misleading information.

\section{TEST, MAINTENANCE, EDUCATION AND TRAINING}

\section{Discussion}

Digital control raises the level of sophistication required of the technicians maintaining the plants. They may have difficultv diagnosing and correcting failures in the advanced $I \& C$. The customary repair approach is identification and replacement of whole PC boards tollowed by off-line servicing on-site or by the vendor. This is generally effective but intermittent problems are difficult to locate and difficult to assure that the repair is successful. Test procedures and frequency that take advantage of tault tolerance and self-diagnostic methods require evaluation. 


\section{Approach}

The test, diagnostic, training and maintenance procedures for license applications for advanced reactors will be examined for thoroughness. Time and motion study analyses may be performed to assure in-depth test and maintenance $\mathrm{ca} a$ be performed according to schedules. The test and diagnostic procedures will be examined for completeness to assure safe operation.

\section{MAN-MACHINE INTERFACE}

\section{Discussion}

The trend in the advanced control rooms is toward optimized presentation of the critical plant data that must be surveyed, analyzed and comprehended by the operator crews. Reduced staffing, integration of operator interface functions for all systems to achieve uniformity of function and appearance, simplification of plant monitoring and control, incorporation of plant-wide automation, challenge of operators to assure alertness, and safe operation under accident conditions require investigation.

In the absence of direct operating experience with advanced control rooms for the advanced reactors, reliance must be placed on models of operator reaction with the new displays and controls using simularors and mock-ups.

\section{Approach}

Models will be constructed of the man-machine interface under normal and accident conditions of varying severity and under varying degrees of degradation. Particular concerns are: operation under accident conditions with reduced staffing, the ability tw incr ase staff under emergencies, the reliability and effectiveness of an indication under accident conditions, whether the reduced information set will provide the necessary information for diagnosis of upset conditions, and decision times under this new configuration. Digital controls raise the level of sophistication above that required for the current generation of the reactors. Automated diagnostic systems and computerized procedures will play an important role in maintaining and inspecting such systems. Completeness and adequacy of these procedures needs evaluation.

\section{ADEQUACY OF CODES, GUIDES, AND STANDARDS FOR EVALUATING ADVANCED I\&C.}

\section{Discussion}

Advances in I\&C technology offer many advantages in functionality and cost. However, there are areas, both in terms of the equipment as well as the design process, where existing industry codes, standards and regulatory requirements are not directly applicable. In these areas, the standards community has initiated efforts to remedy this situation so that the benefits of modern electronics technology can be realized. EPRI, through its ALWR Steering Committee, is working with industry and regulatory participants to develop a user consensus and establish the gruund rules for standards. Examples of work through standards committees are: ANSI/IEEE-ANS7-4.3.2-1 982, "Application Criteria for Programmable Digital Computer Systems of Nuclear Power Generating Stations" and IEC Standard, Pub!tcation 800, "Software for Computers in the Safety Systems of Nuclear Power Stations". These and other documents are needed to establish a review plan with acceptance criteria for determining the adequacy of the submitted designs. Existing regulatory guidance, while containing the framework for determining adequacy, may require modification to incorporate the latest advances in I\&C technology.

\section{Approach}

Determining the adequacy of codes, guides, and standards for evaluating advanced $I \& C$ requires a systematic approach. This begins as a large matrix with issues/concerns arrayed along one axis with the guidance documents addressing the issue/concern arrayed along the other axis. Initial matrix elements would be in the form of checks if the document address the issue/concern at all. When the matrix is complete at this level, it will provide a scoping of the codes, guides and standards. The guidance identified as relevant, will then be reanalyzed to determine the depth and adequacy of the guidance. From this, recummendations may be made as to the need for further guidance development by industry or the NRC.

\section{SELECTED BIBLIOGRAPHY}

[ 1] M.A. Azarm, et al., "Evaluation of Reliability Technology Applicable to LWR Operational Safiety," NUREG/CR- +618. BNL-NIJREG-.51995. August 1988.

[ 2 I M.A. Azarm, R.A. Bari. T-L. Chu and L. Oliveria. "Level-1 Internal Event PRA for the High Flux Beam Reactor," Volumes I \& 2, Rev. 1, Brookhaven National Laboratory. July 1990 
[ 3] M.A. Azarm and W.E. Vesely, et al., "System Unavailability Indicators: Summary Report," Volume 1 \& 2 Draft NUREG/CR, March 1991.

[ 4] J.L. Boccio, W.E. Vesely, M.A. Azarm, et al., "Validation of Risk-Based Performance Indicators: Safety System Function Trends," NUREG/CR-5323, BNL-NUREG-52186, October 1989.

[ 5] R.R. Fullwood, 1988, "Review of Pipe-Break Probability Assessment Methods and Data for Application to the Advanced Neutron Source Project for Oak Ridge National Laboratory," (internal preliminary report, final report in preparation:)

[6] R.R. Fulliwood and R.E. Hall, "Projection of Future Technologica! Needs of the U.S. Nuclear Regulatory Commission over the Next Decade," Letter report to I.J. Lazenick, USNRC, November 1989.

[ 7] R.R. Fullwood and R.E. Hall, 1990, "PRAISDPD: An Aging Pipe Reliability Analysis PC Code," in The Role of Personal Computers in Probabilistic Safety Assessment and Decision Making, Elsevier, London.

[ 8] R.R. Fullwood, D. Selby (ORNL) and F. Peretz (ORNL), 1988, "PRA in Preconceptual Design," TANSAO, 56, 1-626, pp 338-339.

[ 9] W.E. Gunther, "Power Electronic Switching Devices: Their Role in the Nuclear Industry," BNL Technical Report, April 1990.

[10] R.E. Hall, R.R. Fullwood and J.L. Boccio, "Preliminary Program Plan for the Heavy Water Moderated and Cooled Production Reactor: Reliability, Availability, Maintainability and Inspectability," BNL-NPR-HWR-1, May 1990.

[11] E. Lofgren et al., 1988, "Guidance for Using Reliability Programs to Defend against Common-Ciuse Failures," BNL Technical Report A3282-6-16-88.

[12] E. Lofgren, et al., 1991, "Issues and Approaches for Using Equipment Reliability Alert Levels," NUREG/CR-5611, BNL-NUREG-52251, (in publication).

[13] P.K. Samanta, et al., "Evaluation of Risks Associated with AOT and STI Requirements at the ANO-I Nuclear Power Plant," NUREG/CR-5200, 'S. VL-NUREG-52024, August 1988.

[14] P.K. Samanta, et al., "Study of Operational Risk-Based Configuration Control," Draft NUREG/CR-5461, BNL-NUREG-52261, September 1990.

[15] W.E. Vesely, et al., "Evaluation of Diesel Unavailability and Risk-Effective Surveillance Test Intervals," NUREG/CR-4810, BNL-NUREG-52022. May 1987.

\section{DISCLAIMER}

an work sponsored by an agency of the United States: Government. Neither the Inited States Government nor any agency therest, nor any of their

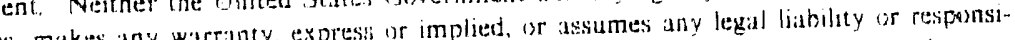
werstuct, or

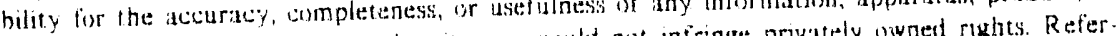
prexess disclosed, or represents that its use would not iniringe pryately owned rishts. Refer. ence herein to any specific commercial product, process, ur service by trade thame, iredemask manufacturer, or otherwise does not necessarily constitute or imply its endorsement, recommendation, or fivoring by the United States Government or any agency theres and opinions of authors expressed herein (i) not necessarily state or reflect those sf the United States Government or any agency theresf 


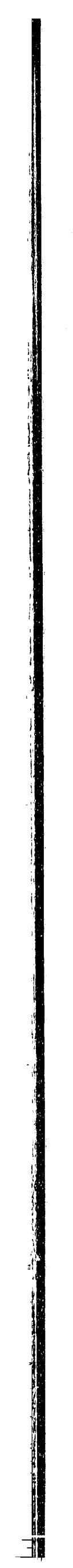

